\title{
miR-152 may function as an early diagnostic and prognostic biomarker in patients with cervical intraepithelial neoplasia and patients with cervical cancer
}

\author{
DONGMEI YANG $^{1}$ and QIUMEI ZHANG ${ }^{2}$ \\ ${ }^{1}$ Department Two of Gynecology; ${ }^{2}$ Outpatient Department of Obstetrics and Gynecology, \\ Linyi People's Hospital, Linyi, Shandong 276003, P.R. China
}

Received July 15, 2017; Accepted February 15, 2019

DOI: $10.3892 / \mathrm{ol} .2019 .10233$

\begin{abstract}
Previous studies have demonstrated that circulating miRNAs are effective biomarkers of various types of cancer. It has also been indicated that miR-152 is upregulated in cervical cancer. However, whether miR-152 may be used as an early detection method for patients with cervical cancer is yet to be elucidated. The results of the current study demonstrated that miR-152 levels were the lowest in healthy controls, high in patients with cervical intraepithelial neoplasia (CIN), and the highest in patients with cervical cancer. Furthermore, miR-152 levels in peripheral blood were higher in patients with high-grade CIN compared with those with low-grade CIN. It was also demonstrated that miR-152 levels increased as the clinical stage of cervical cancer advanced. Compared with healthy controls, squamous cell carcinoma antigen (SSC-Ag) levels were significantly higher in patients with cervical cancer. However, no significant differences were identified in patients with CIN, indicating that SCC-Ag could not be used for the early detection of CIN. In contrast, miR-152 was elevated along with SCC-Ag in patients with CIN and cervical cancer. Receiver operating characteristic (ROC) analysis demonstrated that miR-152 preferentially distinguished patients with CIN (95\% confidence interval, $0.688-0.973 ; \mathrm{P}<0.001)$ and patients with cervical cancer (95\% confidence interval, 0.817-0.996; $\mathrm{P}<0.001$ ) from healthy controls. Additionally, miR-152 levels were markedly reduced in patients with cervical cancer who received chemotherapy (28 patients) or chemotherapy and radiation therapy (22 patients). In conclusion, the level of miR-153 in peripheral blood may be utilized as an effective biomarker for the early detection of cervical cancer, thus decreasing the requirement
\end{abstract}

Correspondence to: Dr Qiumei Zhang, Outpatient Department of Obstetrics and Gynecology, Linyi People's Hospital, 27 Jiefang Road, Linyi, Shandong 276003, P.R. China

E-mail: zhangqiumei00@sina.cn

Key words: microRNA-152, cervical intraepithelial neoplasia, cervical cancer, early biomarker for invasive cervical biopsies. Furthermore, it may be utilized to predict the most effective form of treatment for patients with cervical cancer.

\section{Introduction}

Cervical cancer is one of the most common cancers amongst women worldwide (1). The persistent infection of high-risk human papillomavirus is associated with a high incidence of cervical cancer $(2,3)$. According to histological phenotypes, cervical cancer is divided into two types: Squamous cell carcinoma (SCC; 80\%) and adenocarcinoma ( 5-20\%) (4). SCC primarily originates from cervical intraepithelial neoplasia (CIN), but adenocarcinoma results from intraepithelial adenocarcinoma and glandular dysplasia $(5,6)$.

It has been determined that the most utilized biomarker for cervical cancer is the squamous cell carcinoma antigen (SCC-Ag) (7), and that this antigen is effective for the detection of advanced cervical cancer $(8,9)$. It was revealed that the detection rate of stage III, IV and recurrent malignancies were $76.4,76.9$ and $87 \%$, respectively (10). However, the detection rate of SCC-Ag is relatively low in early stage tumors (10). Therefore, it is necessary to identify novel biomarkers for the early detection of cervical cancer, particularly for high-grade CIN (CIN II/III).

MicroRNAs (miRNAs, miRs) are small, endogenous, single-stranded RNAs consisting of 22 nucleotides (11). The abnormal expression of various miRNAs have been extensively demonstrated in certain types of tumor $(12,13)$. Previous studies have indicated that circulating miRNAs possess diagnostic value and suitability for the detection of tumors $(12,14)$. For instance, the abnormal expression of miRNA-145 and miRNA-338 was identified in serum and sputum samples of patients with chronic obstructive pulmonary disease and asthma (15). In addition, decreased miR-433 and miR-133b levels in the blood may predict the progression of Parkinson's disease (16). Furthermore, miR-152 was previously demonstrated to be upregulated in cervical cancer cells (17). A previous study indicated that miR-152 acts as an attractive biomarker for the prediction of cancer prognosis and development (18). A reduction of circulating miR-152 can be applied for the early detection of lung, colorectal, breast and non-small 
cell lung cancer by screening cancerous tissues from various benign lesions $(19,20)$. However, whether miR-152 can be utilized for the early detection of cervical cancer is yet to be elucidated.

In the present study, the level of circulating miR-152 in patients with low-grade CIN (CIN I), high-grade CIN (CIN II-III) and cervical cancer was determined, and its potential diagnostic value was assessed.

\section{Materials and methods}

Study design. A total of 150 patients (50 patients with cervical cancer, 50 patients with CIN and 50 healthy controls) were enrolled in the present study from Linyi People's Hospital (Shandong, China) between April 2015 and March 2016. The research protocol utilized in the present study was approved by Linyi People's Hospital (Shandong China) and written informed consent was obtained from all patients prior to enrollment. The patients had not received any treatment prior to surgery. The inclusion criteria were: i) Diagnosis with cervical cancer by two senior pathologists; ii) stage IA2-IIA2 cervical cancer, classified according to the International Federation of Gynecology and Obstetrics (2009) (21); iii) a radical hysterectomy and pelvic lymphadenectomy as a method of treatment; and iv) availability of the clinical and pathological data. Exclusion criteria: Patients with active infections, HPV infections, chronic inflammatory disease and histopathologically undetermined cervical abnormalities.

Among patients with cervical cancer, 15 were diagnosed with stage I, 15 with stage II, and 20 with stage III-IV. In addition, 15 patients with CIN were diagnosed with CIN I, 15 were diagnosed with CIN II, and 20 were diagnosed with CIN III. A total of 35 SCC and 15 adenocarcinoma tissue samples were collected from the patients. Blood samples were collected from all patients prior to and following chemotherapy (28 patients) or chemotherapy and radiation therapy (22 patients). The characteristics of each patient enrolled in the current study are presented in Table I.

Measurement of serum SCC-Ag levels. Serum SCC-Ag levels were determined using microparticle enzyme immunoassay (MEIA) with a human SCC-Ag ELISA kit (xy-E10281; Shanghai Xinyu Biotechnology Co. Ltd., Shanghai, China). MEIA was measured by AxSym automated chemiluminescent analyzer from Abbott Diagnostics. Samples were read at $450 \mathrm{~nm}$ using a microplate reader.

RNA extraction. Whole blood samples $(5 \mathrm{ml})$ were collected in tubes containing EDTA. Total RNA was extracted using RNAzol LS (Vigorous Biotechnology, Beijing, China), according to the manufacturer's protocol. The concentration and purity of the RNA samples were determined using the ratio of optical density (OD) 260/280.

Reverse transcription quantitative polymerase chain reaction ( $R T$ - $q P C R)$. RNA was reverse transcribed into cDNA using a PrimeScript One Step RT-PCR kit (cat. no. C28025-032; Invitrogen; Thermo Fisher Scientific, Inc., Waltham, MA, USA). In brief, $5 \mu \mathrm{l}$ RNA template was mixed with $25 \mu 12 \mathrm{X}$ reaction buffer, $2 \mu \mathrm{l} 10 \mu \mathrm{M}$ RT-primer, 2.75 $\mu \mathrm{l}$ RT-PCR MIX and $12.75 \mu \mathrm{l}$ RNase-free $\mathrm{H}_{2} \mathrm{O}$. The sequences of the primers used in RT-PCR were as follows: miR-152-RT, 5'-GTCGTATCCAGTGCAGGG TCCGAGGTATTCGCACTGGATACGACAGTCGG-3'; and U6-RT, 5'-GTCGTATCCAGTGCAGGGTCCGAGGTATTC GCACTGGATACGACAAAATG-3'. The reaction procedure for reverse transcription was: Pre-denaturing for $5 \mathrm{~min}$ at $94^{\circ} \mathrm{C}$, followed by 40 cycles of denaturing for $30 \mathrm{sec}$ at $94^{\circ} \mathrm{C}$, annealing for $30 \mathrm{sec}$ at $55^{\circ} \mathrm{C}$ and elongation for $30 \mathrm{sec}$ at $72^{\circ} \mathrm{C}$, and final elongation at $72^{\circ} \mathrm{C}$ for $10 \mathrm{~min}$. To quantify the relative mRNA levels, qPCR was performed using SYBR ${ }^{\circledR}$ Green Supermix (Bio-Rad Laboratories, Inc., Hercules, CA, USA) in an iCycler iQ Real Time PCR Detection system. The PCR amplifications were performed in a $10 \mu \mathrm{l}$ reaction system containing $5 \mu \mathrm{l}$ SYBR Green Supermix, $0.4 \mu \mathrm{l}$ forward primer, $0.4 \mu \mathrm{l}$ reverse primer, $2.2 \mu \mathrm{l}$ double-distilled water and $2 \mu \mathrm{l}$ template cDNA. The sequences of the primers for qPCR were as follows: miR-152 forward, 5'-GCGCAGGTTCTGTGATACACTC-3'; U6 forward, 5'-GCGCGTCGTGAAGCGTTC-3'; universal reverse primer, 5'-GTGCAGGGTCCGAGGT-3'. The thermocycling conditions were as follows: $95^{\circ} \mathrm{C}$ for $10 \mathrm{~min}$, followed by 50 cycles at $95^{\circ} \mathrm{C}$ for $10 \mathrm{sec}, 55^{\circ} \mathrm{C}$ for $10 \mathrm{sec}, 72^{\circ} \mathrm{C}$ for $5 \mathrm{sec}, 99^{\circ} \mathrm{C}$ for $1 \mathrm{sec}, 59^{\circ} \mathrm{C}$ for $15 \mathrm{sec}$, and $95^{\circ} \mathrm{C}$ for $2 \mathrm{~min}$. The samples were then cooled to $40^{\circ} \mathrm{C}$. The relative expression levels were calculated using the $2^{-\Delta \Delta \mathrm{Cq}}$ method (22) and experiments were repeated in triplicate. U6 was used as an internal control.

Statistical analysis. Data were analyzed using SPSS 13.0 software (SPSS, Inc., Chicago, IL, USA). Data are expressed as the mean \pm standard deviation. Statistical analysis was performed using Student's t test or one-way analysis of variance followed by Tukey post hoc test. Receiver operating characteristic (ROC) curves were used to assess miR-152 as a biomarker and the area under the curve was determined. $\mathrm{P}<0.05$ was considered to indicate a statistically significant result.

\section{Results}

miR-152 is elevated in the peripheral blood of patients with cervical cancer. The level of miR-152 in patients with cervical cancer was determined. The results revealed that levels of miR-152 in the peripheral blood was increased in patients with cervical cancer and patients with CIN compared with healthy controls. The highest expression levels of miR-152 were identified in patients with cervical cancer (Fig. 1). The median serum miRNA-152 level in healthy controls, patients with CIN and patients with cervical cancer were $0.23 \pm 0.11,1.78 \pm 0.56$ and $3.56 \pm 0.93$, respectively ( $\mathrm{P}<0.001$ vs. healthy control; ANOVA followed by Turkey post hoc test).

miR-152 distinguishes patients with CIN and patients with cervical cancer from healthy controls. The ROC curve indicated that miR-152 levels in the peripheral blood of patients may be used to distinguish patients with CIN from healthy controls, with an ROC curve area of 0.831 with a $95 \%$ confidence interval (CI) of 0.688-0.973 ( $\mathrm{P}<0.001$; Fig. 2A). Furthermore, the peripheral blood levels of miR-152 may be used to differentiate patients with cervical cancer from healthy controls, with an ROC curve area of 0.935 (95\% CI, 0.817-0.996; P<0.001; Fig. 2B). 
Table I. Characteristics of patients enrolled in the present study.

\begin{tabular}{|c|c|c|c|c|c|}
\hline Characteristic & Cervical cancer $(n=50)$ & CIN I (n=15) & CIN II (n=15) & CIN III (n=20) & Healthy controls $(n=50)$ \\
\hline Age, years & $48.0 \pm 15.2$ & $38.0 \pm 8.9$ & $35.3 \pm 9.5$ & $36.2 \pm 10.2$ & $43.0 \pm 7.6$ \\
\hline \multicolumn{6}{|l|}{ Histological type } \\
\hline $\mathrm{SCC}, \mathrm{n}$ & 39 & 0 & 0 & 0 & 0 \\
\hline Adenocarcinoma, $n$ & 11 & 0 & 0 & 0 & 0 \\
\hline \multicolumn{6}{|l|}{ Clinical stage } \\
\hline $\mathrm{I}, \mathrm{n}$ & 15 & 0 & 0 & 0 & 0 \\
\hline $\mathrm{II}, \mathrm{n}$ & 15 & 0 & 0 & 0 & 0 \\
\hline III-IV, n & 20 & 0 & 0 & 0 & 0 \\
\hline
\end{tabular}

CIN, cervical intraepithelial neoplasia; SCC, squamous cell carcinoma.

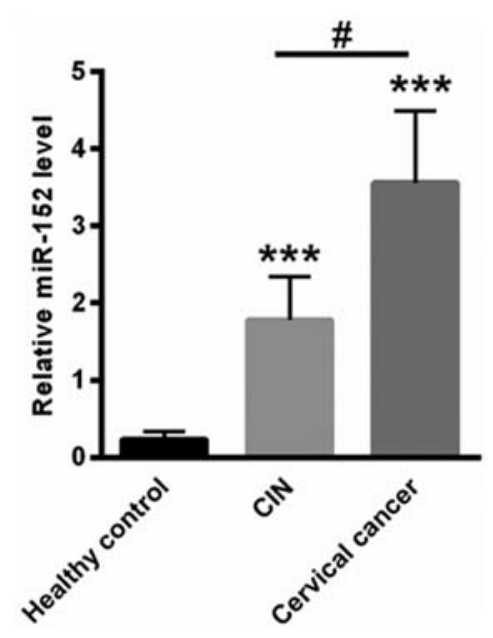

Figure 1. miR-152 levels were elevated in the peripheral blood of patients with cervical cancer. ${ }^{* * *} \mathrm{P}<0.001$ vs. healthy control; ${ }^{\text {}} \mathrm{P}<0.05$ vs. CIN (one-way analysis of variance followed by Tukey post hoc test). miR-152, microRNA-152; CIN, cervical intraepithelial neoplasia.

Expression levels of miR-152 in the peripheral blood increase along with the stage of cervical cancer. Since elevated SCC-Ag levels in patients prior to treatment is closely associated with advanced international federation of gynecology and obstetrics stage (23), the present study assessed the association between SCC-Ag and miR-152 levels. As presented in Fig. 3A, the median level of SCC-Ag prior to treatment in early stage CIN and cervical cancer was lower compared with that in advanced disease stages (healthy controls, $0.52 \pm 0.34 \mathrm{ng} / \mathrm{ml}$; CIN I-II group, $0.68 \pm 0.38 \mathrm{ng} / \mathrm{ml}$; CIN III group, $0.75 \pm 0.42 \mathrm{ng} / \mathrm{ml}$; cervical cancer I, $1.58 \pm 0.46 \mathrm{ng} / \mathrm{ml}$; cervical cancer II, $2.87 \pm 1.35 \mathrm{ng} / \mathrm{ml}$; and cervical cancer III-IV, $5.87 \pm 1.72 \mathrm{ng} / \mathrm{ml}$ ). Furthermore, the present study assessed the expression of miR-152 at different stages of cervical cancer. As presented in Fig. 3B, compared with healthy controls $(0.23 \pm 0.11)$, the level of miR-152 was $1.05 \pm 0.63$ for the CIN I-II group ( $\left.{ }^{*} \mathrm{P}<0.05\right), 2.43 \pm 0.71$ for the CIN III group $\left({ }^{*} \mathrm{P}<0.05\right), 2.87 \pm 0.51$ for the cervical cancer stage I group $\left({ }^{* *} \mathrm{P}<0.01\right), 3.42 \pm 0.97$ for the cervical cancer stage II group $\left({ }^{* *} \mathrm{P}<0.01\right)$ and $4.76 \pm 0.87$ for the cervical cancer stage III-IV group $\left.{ }^{* * *} \mathrm{P}<0.001\right)$. These data indicated that the level of miR-152 increased with cervical cancer stage, and was positively associated with serum SCC-Ag levels.

miR-152 did not identify SCC and adenocarcinoma. The present study assessed the level of miR-152 in SCC and adenocarcinoma tissues. However, no significant differences were observed in the miR-152 levels of SCC $(3.12 \pm 0.78)$ and adenocarcinoma tissues (3.78 \pm 1.02 ; Fig. 4).

miR-152 levels decrease following treatment. The level of total serum SCC-Ag of 50 patients with cervical cancer were assessed following treatment with chemotherapy or chemotherapy and radiation therapy. Prior to treatment, the median level of SCC-Ag was $4.41 \pm 1.05 \mathrm{ng} / \mathrm{ml}$ (Fig. 5A). However, the level of serum SCC-Ag was decreased to $0.74 \pm 0.35 \mathrm{ng} / \mathrm{ml}$ following treatment (Fig. 5A). In addition, the average level of miR-152 prior to treatment was $3.08 \pm 1.22$, which was reduced to $0.43 \pm 0.34$ following treatment (Fig. $5 \mathrm{~B}$ ). These data indicated that miR-152 levels in peripheral blood may be an effective biomarker for cervical cancer screening.

\section{Discussion}

At present, it is important to identify effective disease biomarkers that detect early stage cancer, and thus improve survival rate (24), particularly for high-risk patients $(8,24)$. The SCC-Ag is extensively applied clinically as a prognostic and diagnostic biomarker for patients with cervical cancer $(7,24)$. However, this antigen is not significantly increased during the early stages of disease (25). Therefore, it is necessary to identify novel biomarkers for the early detection of cervical cancer.

Previous studies have indicated that miRNAs serve important regulatory roles in the progression of cervical cancer; miRNAs primarily regulate cancer cell proliferation, migration and apoptosis $(26,27)$. miRNAs are also suggested to be stable in the tissues and blood $(28,29)$, with circulating miRNAs acting as 'extracellular communication RNAs' between various tissues $(30,31)$. Compared with tissue-based miRNA profiling, blood miRNAs may be used as non-invasive, sensitive and specific biomarkers in certain 

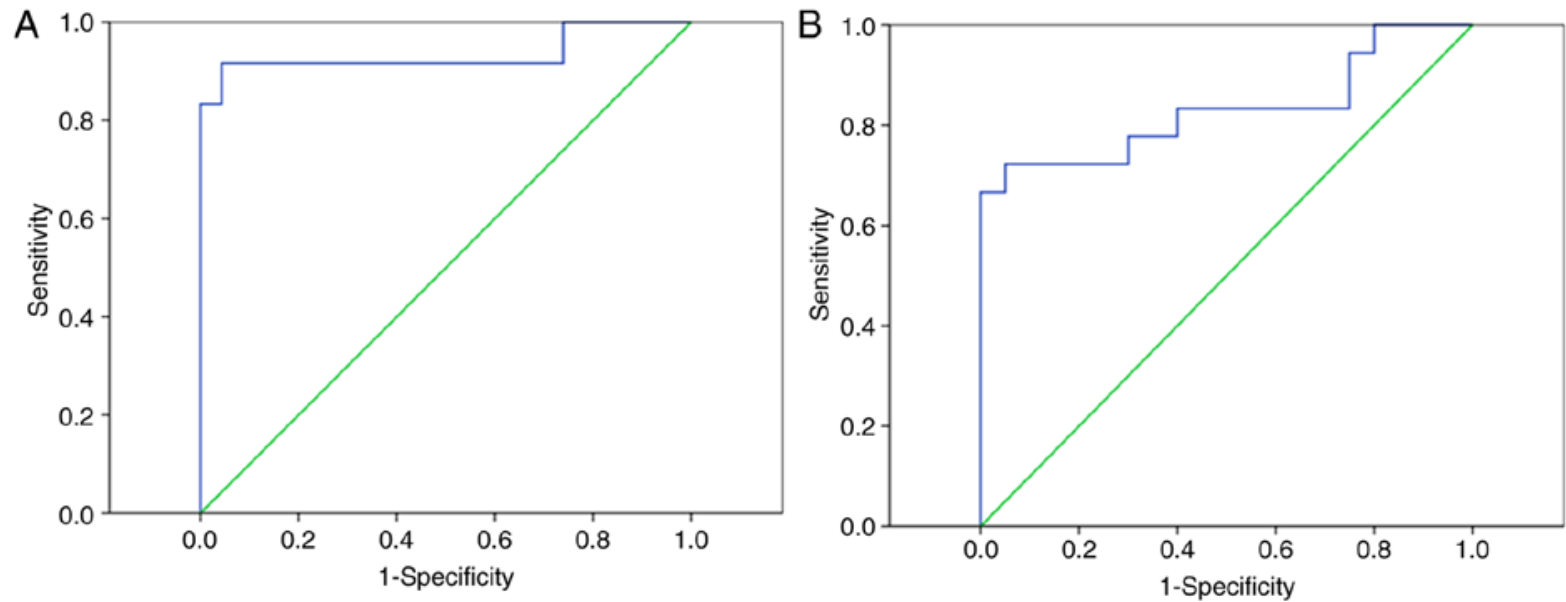

Figure 2. miR-152 could differentiate patients with CIN from patients with cervical cancer from healthy controls. ROC curves indicating that (A) the peripheral blood levels of miR-152 may differentiate patients with CIN from healthy controls and (B) the peripheral blood levels of miR-152 may differentiate patients with cervical cancer from healthy controls. miR-152, microRNA-152; ROC, receiver operating characteristic; CIN, cervical intraepithelial neoplasia.

A

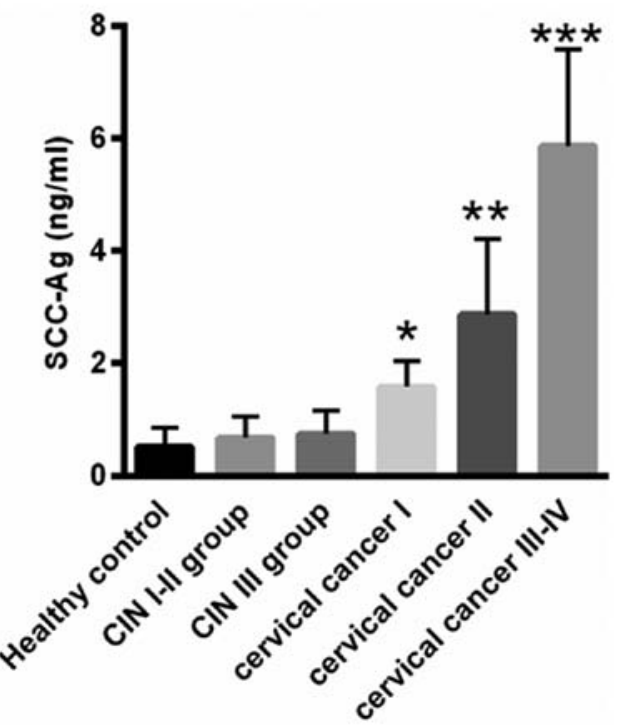

B

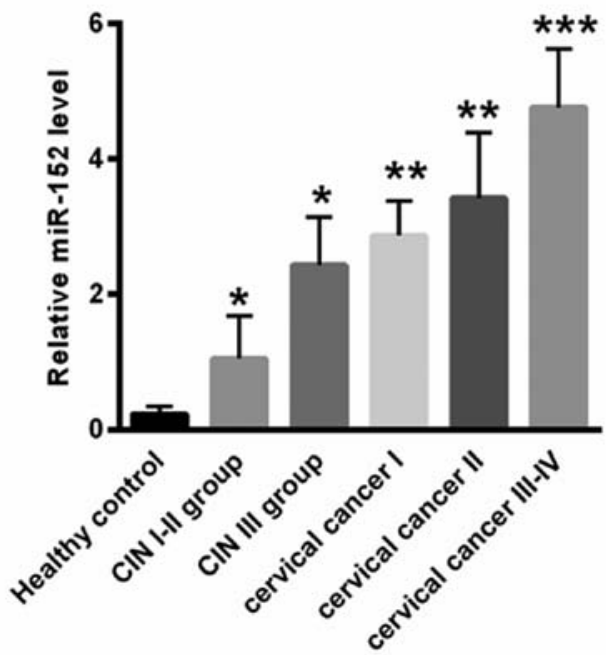

Figure 3. The level of miR-152 was elevated with advanced cervical cancer stage. (A) The median level of SCC-Ag prior to treatment in the early stages of patients with CIN and cervical cancer was lower compared with that of advanced stages. (B) Reverse transcription-quantitative polymerase chain reaction analysis of the miR-152 expression level at different stages of $\mathrm{CIN}$ and cervical cancer. ${ }^{*} \mathrm{P}<0.05,{ }^{* * *} \mathrm{P}<0.01,{ }^{* * * *} \mathrm{P}<0.001$ vs. healthy controls (one-way analysis of variance followed by Turkey post hoc test). miR-152, microRNA-152; SCC-Ag, squamous cell carcinoma antigen; CIN, cervical intraepithelial neoplasia.

tumors $(32,33)$. For instance, the level of miR-146a-5p in serum exosomes may predict the therapeutic effects of cisplatin in non-small cell lung cancer (34). In addition, circulating exosomal miR-125a-3p was demonstrated to be a novel biomarker used for the early detection of colon cancer (13). These results indicate that circulating miRNAs may be effective biomarkers for the early detection of certain types of cancer.

The present study demonstrated that levels of miR-152 were the lowest in healthy controls, higher in CIN patients and further increased in patients with cervical cancer. Furthermore, the level of miR-152 in peripheral blood was higher in patients with high-grade CIN compared with those with low-grade CIN. At present, cervical cancer tumor markers, including SCC-Ag, carcinoembryonic antigen, cytokeratin 19 , cancer antigen 125 and carbohydrate antigen
19-9, are widely utilized in clinical settings (35). However, these tumor markers are ineffective at identifying patients with CIN. The present study assessed the serum SCC-Ag levels of patients with cervical cancer. Compared with healthy controls, SSC-Ag levels were significantly higher in patients with cervical cancer. However, no significant differences were identified in patients with CIN, indicating that SCC-Ag could not be used as an early detection marker for CIN. Additionally, low expression levels of SCC-Ag were identified in the peripheral blood of healthy controls. Unlike SCC-Ag, an upregulation of miR-152 was detected in patients with CIN. Therefore, miR-152 was demonstrated to be a more sensitive and specific screening method compared with SCC-Ag for patients with CIN. By detecting changes of miR-152 expression in peripheral blood, patients with a high-risk of cervical cancer may be differentially identified from healthy controls. 


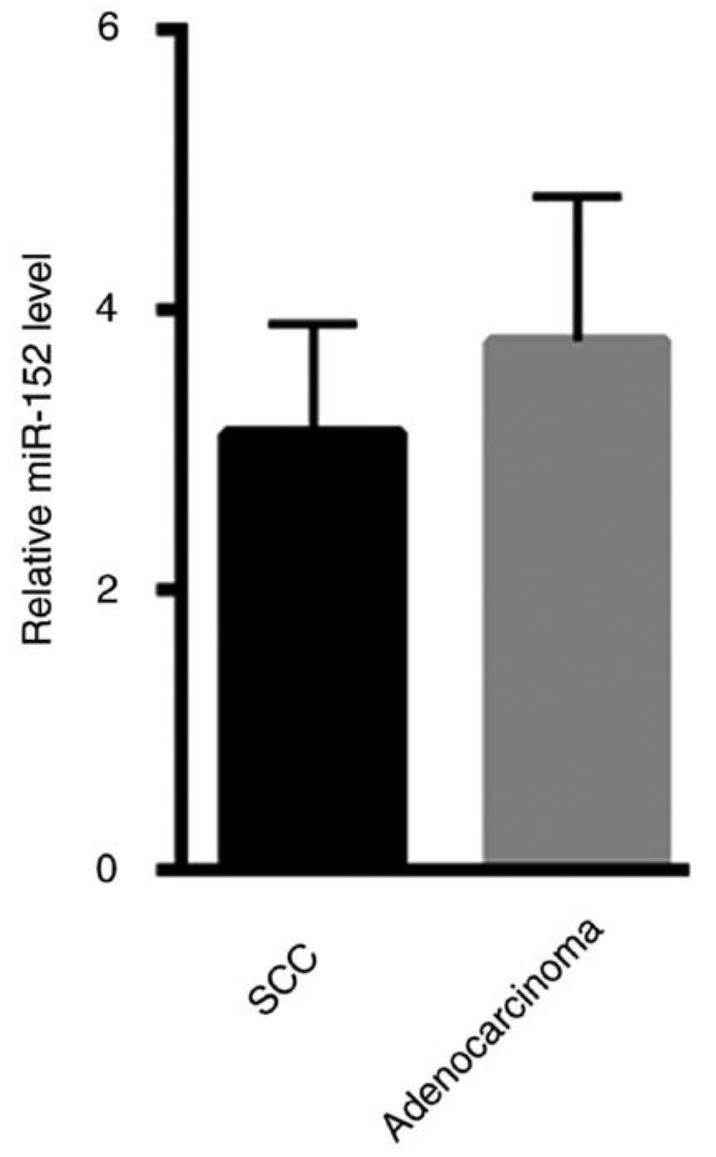

Figure 4. No significant differences were observed in miR-152 levels between SCC and adenocarcinoma tissues. miR-152, microRNA-152; SCC, squamous cell carcinoma.
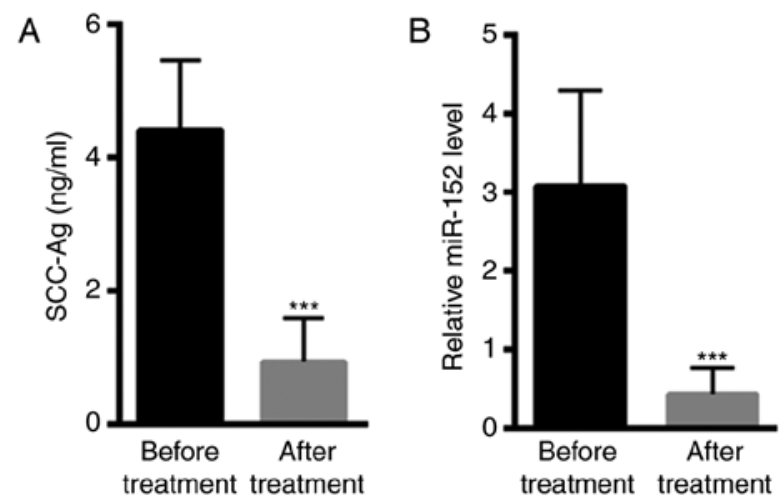

Figure 5. Decreased miR-152 levels following treatment. (A) Serum SCC-Ag levels were decreased following treatment (28 received chemotherapy and 22 received chemotherapy combined with radiation therapy). (B) The average level of miR-152 was decreased following treatment. ${ }^{* * *} \mathrm{P}<0.001$ vs. control (paired t-test). miR-152, microRNA-152; SCC-Ag, squamous cell carcinoma antigen.

The present study assessed the potential mechanism by which increased miR-152 levels modulates the malignant progression of cervical cancer. It has been suggested that the phosphatase and tensin homolog (PTEN), a tumor suppressor, is decreased in patients with nasopharyngeal carcinoma (NPC) and is associated with the pathological grade and clinical stage of NPC (36). It has been demonstrated that the reduced expression of PTEN in patients with NPC may be associated with the upregulation of miR-152, thereby inhibiting cell apoptosis and enhancing cancer cell proliferation and migration during NPC development (36). Similarly, the results of the present study indicated that increased miR-152 levels are identified in patients with CIN and patients with cervical cancer. Further studies are required to investigate the impact of increased miR-152 in the peripheral blood of patients with cervical cancer on the expression of PTEN, and whether this may enhance malignant changes.

In conclusion, the level of miR-152 in peripheral blood may be utilized as an effective biomarker for the early detection of cervical cancer, thus decreasing the requirement for invasive cervical biopsies. It may also predict the most appropriate method of treatment for patients with cervical cancer. However, further studies are required to fully elucidate the functional role of miR-152 in cervical cancer.

\section{Acknowledgements}

Not applicable.

\section{Funding}

The present study was supported by a grant from Hunan Province supporting fund of Linyi People's Hospital (SDLYH-20170812; Shandong, China).

\section{Availability of data and materials}

The datasets used and/or analyzed during the current study are available from the corresponding author on reasonable request.

\section{Authors' contributions}

DY performed the experiments, analyzed the data and wrote the paper. QZ designed the experiments, analyzed the data and gave final approval of the version to be published. Both authors read and approved the final manuscript.

\section{Ethics approval and consent to participate}

The present study was approved by the Research Ethics Committee of Linyi People's Hospital (Linyi, Shandong, China) and all the patients have provided written informed consent for this study.

\section{Patient consent for publication}

All patients provided written informed consent for the publication of data in this study.

\section{Competing interests}

The authors declare that they have no competing interests.

\section{References}

1. Luttmer R, De Strooper LM, Steenbergen RD, Berkhof J, Snijders PJ, Heideman DA and Meijer CJ: Management of high-risk HPV-positive women for detection of cervical (pre) cancer. Expert Rev Mol Diagn 16: 961-974, 2016. 
2. El-Zein M, Richardson L and Franco EL: Cervical cancer screening of HPV vaccinated populations: Cytology, molecular testing, both or none. J Clin Virol 76 (Suppl 1): S62-S68, 2016.

3. Jayasinghe Y, Rangiah C, Gorelik A, Ogilvie G, Wark JD, Hartley S and Garland SM: Primary HPV DNA based cervical cancer screening at 25 years: Views of young Australian women aged 16-28 years. J Clin Virol 76 (Suppl 1): S74-S80, 2016.

4. Hasahya OT, Berggren V, Sematimba D, Nabirye RC and Kumakech E: Beliefs, perceptions and health-seeking behaviours in relation to cervical cancer: A qualitative study among women in Uganda following completion of an HPV vaccination campaign. Glob Health Action 9: 29336, 2016.

5. Lofters A and Vahabi M: Self-sampling for HPV to enhance uptake of cervical cancer screening: Has the time come in Canada? CMAJ 188: 853-854, 2016.

6. Lowy DR: HPV vaccination to prevent cervical cancer and other HPV-associated disease: From basic science to effective interventions. J Clin Invest 126: 5-11, 2016.

7. Salvatici M, Achilarre MT, Sandri MT, Boveri S, Vanna Z and Landoni F: Squamous cell carcinoma antigen (SCC-Ag) during follow-up of cervical cancer patients: Role in the early diagnosis of recurrence. Gynecol Oncol 142: 115-119, 2016.

8. Micke O, Prott FJ, Schäfer U, Tangerding S, Pötter R and Willich N: The impact of squamous cell carcinoma (SCC) antigen in the follow-up after radiotherapy in patients with cervical cancer. Anticancer Res 20: 5113-5115, 2000.

9. Nozawa S, Kojima M, Tukazaki K, Sakayori M, Iizuka R and Kagiyama N: In vitro and in vivo induction of squamous cell carcinoma antigen (SCC) in a uterine cervical cancer cell line (SKG-IIIa) with peplomycin and sodium butyrate. Asia Oceania J Obstet Gynaecol 16: 153-160, 1990.

10. Yamashita Y, Uehara T, Hasegawa M, Deng Z, Matayoshi S, Kiyuna A, Kondo S, Maeda H, Ganaha A and Suzuki M: Squamous cell carcinoma antigen as a diagnostic marker of nasal inverted papilloma. Am J Rhinol Allergy 30: 122-127, 2016.

11. Yao J, Zhang P, Li J and Xu W: MicroRNA-215 acts as a tumor suppressor in breast cancer by targeting AKT serine/threonine kinase 1. Oncol Lett 14: 1097-1104, 2017.

12. Sempere LF, Keto J and Fabbri M: Exosomal MicroRNAs in breast cancer towards diagnostic and therapeutic applications. Cancers (Basel) 9: E71, 2017.

13. Wang J, Yan F, Zhao Q, Zhan F, Wang R, Wang L, Zhang Y and Huang $X$ : Circulating exosomal miR-125a-3p as a novel biomarker for early-stage colon cancer. Sci Rep 7: 4150, 2017.

14. Zhang ZQ, Meng H, Wang N, Liang LN, Liu LN, Lu SM and Luan Y: Serum microRNA 143 and microRNA 215 as potential biomarkers for the diagnosis of chronic hepatitis and hepatocellular carcinoma. Diagn Pathol 9: 135, 2014.

15. Lacedonia D, Palladino GP, Foschino-Barbaro MP, Scioscia G and Carpagnano GE: Expression profiling of miRNA-145 and miRNA-338 in serum and sputum of patients with COPD, asthma, and asthma-COPD overlap syndrome phenotype. Int J Chron Obstruct Pulmon Dis 12: 1811-1817, 2017.

16. Zhang X, Yang R, Hu BL, Lu P, Zhou LL, He ZY, Wu HM and Zhu JH: Reduced circulating levels of miR-433 and miR-133b are potential biomarkers for Parkinson's disease. Front Cell Neurosci 11: 170, 2017.

17. Tang XL, Lin L, Song LN and Tang XH: Hypoxia-inducible miR-152 suppresses the expression of WNT1 and ERBB3, and inhibits the proliferation of cervical cancer cells. Exp Biol Med (Maywood) 241: 1429-1437, 2016.

18. Miao C, Zhang J, Zhao K, Liang C, Xu A, Zhu J, Wang Y, Hua Y, Tian Y, Liu S, et al: The significance of microRNA-148/152 family as a prognostic factor in multiple human malignancies: A meta-analysis. Oncotarget 8: 43344-43355, 2017.

19. Chen H, Liu H, Zou H, Chen R, Dou Y, Sheng S, Dai S, Ai J, Melson J, Kittles RA, et al: Evaluation of plasma miR-21 and miR-152 as diagnostic biomarkers for common types of human cancers. J Cancer 7: 490-499, 2016.
20. Dou H, Wang Y, Su G and Zhao S: Decreased plasma let-7c and miR-152 as noninvasive biomarker for non-small-cell lung cancer. Int J Clin Exp Med 8: 9291-9298, 2015.

21. Pecorelli S: Revised FIGO staging for carcinoma of the vulva, cervix, and endometrium. Int J Gynaecol Obstet 105: 103-104, 2009.

22. Livak KJ and Schmittgen TD: Analysis of relative gene expression data using real-time quantitative PCR and the 2(-Delta Delta C(T)) method. Methods 25: 402-408, 2001.

23. Wen YF, Cheng TT, Chen XL, Huang WJ, Peng HH, Zhou TC, Lin XD and Zeng LS: Elevated circulating tumor cells and squamous cell carcinoma antigen levels predict poor survival for patients with locally advanced cervical cancer treated with radiotherapy. PLoS One 13: e0204334, 2018.

24. Hung YC, Shiau YC, Chang WC, Kao CH and Lin CC: Early predicting recurrent cervical cancer with combination of tissue polypeptide specific antigen (TPS) and squamous cell carcinoma antigen (SCC). Neoplasma 49: 415-417, 2002

25. Nagamitsu Y, Nishi H, Sasaki T, Takaesu Y, Terauchi F and Isaka K: Profiling analysis of circulating microRNA expression in cervical cancer. Mol Clin Oncol 5: 189-194, 2016.

26. Granados-López AJ, Ruiz-Carrillo JL, Servín-González LS, Martínez-Rodríguez JL, Reyes-Estrada CA, GutiérrezHernández R and López JA: Use of mature miRNA strand selection in miRNAs families in cervical cancer development. Int J Mol Sci 18: E407, 2017.

27. Gao D, Zhang Y, Zhu M, Liu S and Wang X: miRNA expression profiles of $\mathrm{HPV}$-infected patients with cervical cancer in the Uyghur population in China. PLoS One 11: e0164701, 2016.

28. Liu B, Ding JF, Luo J, Lu L, Yang F and Tan XD: Seven protective miRNA signatures for prognosis of cervical cancer. Oncotarget 7: 56690-56698, 2016.

29. Zhao S, Yao D, Chen J and Ding N: Circulating miRNA-20a and miRNA-203 for screening lymph node metastasis in early stage cervical cancer. Genet Test Mol Biomarkers 17: 631-636, 2013.

30. Zhao C, Lu F, Chen H, Zhao F, Zhu Z, Zhao X and Chen H: Clinical significance of circulating miRNA detection in lung cancer. Med Oncol 33: 41, 2016.

31. Ponomaryova AA, Morozkin ES, RykovaEY,ZaporozhchenkoIA, Skvortsova TE, Dobrodeev AY, Zavyalov AA, Tuzikov SA, Vlassov VV, Cherdyntseva NV, et al: Dynamic changes in circulating miRNA levels in response to antitumor therapy of lung cancer. Exp Lung Res 42: 95-102, 2016.

32. Qu K, Zhang X, Lin T, Liu T, Wang Z, Liu S, Zhou L, Wei J, Chang $\mathrm{H}, \mathrm{Li} \mathrm{K}$, et al: Circulating miRNA-21-5p as a diagnostic biomarker for pancreatic cancer: Evidence from comprehensive miRNA expression profiling analysis and clinical validation. Sci Rep 7: 1692, 2017.

33. Sharova E, Grassi A, Marcer A, Ruggero K, Pinto F, Bassi P, Zanovello P, Zattoni F, D'Agostino DM, Iafrate $M$ and Ciminale V: A circulating miRNA assay as a first-line test for prostate cancer screening. Br J Cancer 114: 1362-1366, 2016.

34. Yuwen DL, Sheng BB, Liu J, Wenyu W and Shu YQ: MiR-146a-5p level in serum exosomes predicts therapeutic effect of cisplatin in non-small cell lung cancer. Eur Rev Med Pharmacol Sci 21: 2650-2658, 2017.

35. Dasari S, Wudayagiri R and Valluru L: Cervical cancer: Biomarkers for diagnosis and treatment. Clin Chim Acta 445: $7-11,2015$.

36. Huang S, Li X and Zhu H: MicroRNA-152 targets phosphatase and tensin homolog to inhibit apoptosis and promote cell migration of nasopharyngeal carcinoma cells. Med Sci Monit 22: $4330-4337,2016$ 